\title{
Peri-Implant Tissue Findings in Bone Grafted Oral Cancer Patients Compared to non Bone Grafted Patients without Oral Cancer
}

\author{
Jan Wolff' ${ }^{1}$, Hideki Agata ${ }^{2}$, George K. Sándor ${ }^{3,4}$, Suvi Haimi ${ }^{4}$ \\ ${ }^{1}$ Oral and Maxillofacial Unit, University of Tampere, Tampere, Finland. \\ ${ }^{2}$ Division of Molecular Therapy, Advanced Clinical Research Center, The Institute of Medical Science, The University of \\ Tokyo, Tokyo, Japan. \\ ${ }^{3}$ Department of Oral and Maxillofacial Surgery, University of Oulu, Oulu, Finland. \\ ${ }^{4}$ Regea-Institute for Regenerative Medicine, University of Tampere, Tampere, Finland.
}

\author{
Corresponding Author: \\ Jan Wolff \\ Oral and Maxillofacial Unit, University of Tampere \\ P.O. Box 2000, FI-33521 Tampere \\ Finland \\ Phone: +358405571199 \\ Fax: +358335518498 \\ E-mail: jan.wolff@regea.fi
}

\begin{abstract}
Objectives: The aim of this study was to compare microbiological, histological, and mechanical findings from tissues around osseointergrated dental implants in patients who had undergone tumour resection and subsequent bone grafting with non bone grafted patients without a history of oral cancer and to develop an effective tool for the monitoring of the peri-implant tissues. A third aim was to assess and compare the masticatory function of the two patient groups after reconstruction with dental implants.

Material and Methods: A total of 20 patients were divided into 2 groups. The first group was edentulous and treated with dental implants without the need for bone grafting. The second edentulous group, with a history of oral cancer involving the mandible, received onlay bone grafts with concurrent placement of dental implants. Microbiological, histological, mechanical and biochemical assessment methods, crevicular fluid flow rate, hygiene-index, implant mobility, and the masticatory function were analysed and compared in both patient groups.

Results: The microbiological examinations showed no evidence of the three most common pathogenic bacteria: Porphyromonas gingivalis, Prevotella intermedius, Actinobacillus actinomycetencomitans. A causal relationship between specific microbes and peri-implant inflammation could not be found. All biopsies in both patient groups revealed early signs of soft tissue periimplant inflammation.

Conclusions: The crevicular fluid volume and grade of gingival inflammation around the dental implants were related. Periimplant tissue findings were similar in the two patient groups despite the history of oral cancer and the need for bone grafting at the time of dental implant placement.
\end{abstract}

Keywords: augment bone graft; cancer of the jaw; dental implantation, osseointegrated; mastication; continuity of patient care; patient monitoring.

Accepted for publication: 23 August 2011

To cite this article:

Wolff J, Agata H, Sándor GK, Haimi S. Peri-Implant Tissue Findings in Bone Grafted Oral Cancer Patients Compared to non Bone Grafted Patients without Oral Cancer.

J Oral Maxillofac Res 2011 (Oct-Dec);2(4):e2

URL: http://www.ejomr.org/JOMR/archives/2011/4/e2/v2n4e2ht.pdf

doi: $10.5037 /$ jomr.2011.2402 


\section{INTRODUCTION}

Maxillofacial procedures which restore form and function may result in a host of problems that can affect the quality of life of patients. The focus on patient care has shifted towards preservation of form and function with the careful selection of appropriate reconstruction techniques [1]. Oral implant treatment aims to restore the masticatory and speech function in patients suffering from atrophic jaws or who have undergone tumour resection and subsequent bone grafting with the intention of providing a better quality of life.

The monitoring of dental implant health following tumour surgery may be valuable for such patients. Although oral implants have enjoyed high clinical success rates over the years, complications and failures due to peri-implant diseases remain a challenge [2] It is, therefore, important to identify patients who are at increased risk of developing peri-implantitis at an early stage. Anatomical alterations following tumour resection may make it more difficult for some cancer patients to keep their implant hardware clean []ㅡ. In many cases, initial plaque development around dental implants starts in inaccessible spaces that cannot be properly cleaned by patients. Preventive regimens are simple methods to stop the transition from healthy to diseased implants. At the present time, the monitoring of dental implants is based on an individual recall-system [4]. To date, no general guidelines exist for oral implant care following oral cancer treatment. Cross-sectional and longitudinal studies report the prevalence of peri-implantitis in healthy patients as varying between $28 \%$ and $56 \%$ [ 5 ]. Since clinical signs of peri-implantitis may not always be obvious, it is of importantance to develop an efficient method of monitoring dental implants especially in tumour patients who have undergone reconstructive surgery.

The main objective of this study was to compare the soft tissue findings and treatment outcomes regarding masticatory function in two groups of edentulous patients: those patients with a history of oral cancer treated with dental implants and concurrent bone grafting versus patients with no history of oral cancer and who did not require bone grafting at the time of implant placement. A further objective of this study was to compare different microbiological, histological, mechanical and biochemical assessment methods for implant monitoring in order to develop oral care monitoring tools for patients who have undergone reconstructive surgery and treatment with dental implants.

\section{MATERIAL AND METHODS}

\section{Study design}

This study was conducted in accordance with the Ethical Committee of Hanover University, Hanover, Germany in compliance with the Helsinki Declaration. Ten edentulous adult patients (6 males and 4 females), treated with osseointergrated implants, were enrolled in the study. The second group of patients consisted of 10 patients ( 7 males and 3 females) that had undergone ablative surgery due to early-stage oral squamous cell cancer followed by reconstruction of the left mandible in a two stage operative procedure. The second procedure included the use of autogenous bone blocks and particulate bone from the anterior or posterior iliac crest and the simultaneous placement of Brånemark dental implants.

The average age was 54.3 years with a range of 42 and 67 years. Brånemark implants of 10 to $13 \mathrm{~mm}$ in length with a diameter of $3.75 \mathrm{~mm}$ were used. All implants had been in situ for at least 13 and up to 69 months for an average of 27.8 months and had been loaded with a fullarch metal-resin framework. No patients with a history of radiation therapy were included in this study. None of the patients in either group had any major systemic or metabolic illnesses. All patients in both groups had stopped smoking for at least 6 months before inclusion into this study. Prior to the study a total of 3 patients had been smokers, patient EJ (without a bone graft) and patients WT, DH with a bone graft.

\section{Microbiological evaluation}

A total of forty probes were taken from the twenty patients. With each patient, two different areas of the mouth flora (gingival area) were randomly analysed. Using a sterile polyester fibre-tipped applicator (Falcon, manufactured for Becton Dickonson Vacutainer systems, Franklin Lakes, New Jersey, USA), the first probe on the vestibular aspect was taken $1 \mathrm{~cm}$ caudal to the implant shoulder. The swab was then immediately immersed in a transport medium (Port-A-Cul ${ }^{\circledR}$ Universal-System, Becton Dickonson GmbH, Heidelberg, Germany) to maintain the viability of the aerobic and anaerobic microorganisms during transit.

The second probe was taken using a sterile $0.50 \times 40 \mathrm{~mm}$ diameter blunt needle $\left(\right.$ Sterican $^{\circledR}$, Luer Lock, B. Braun, Melsungen, Germany) connected to a sterile $2 \mathrm{ml}$ syringe (Injekt, B. Braun, Melsungen, Germany). The needle was placed vestibularly into the implant gingival junction with light pressure applied in order to reach the base of the sulcus pocket. Using the syringe, crevicular fluid was aspirated. The needle surface 
was then immediately wiped using a sterile swab. Then, the needle was immediately placed into the transport medium.

The anaerobic and aerobic microorganisms were cultivated on selective and non-selective agar plates for 48 hours in aerobic, microaerophilic, and anaerobic environments. The cultured specimens were identified using the following characteristics: micro-organism morphology, colony appearance, carbohydrate fermentation, amino acid hydrolysis, pattern of fermentation products, and enzyme profiles. The cultivation of microorganisms was evaluated separately based on the guidelines laid down by the American society of Microbiology []], the Centre of disease control [7], and Bergey's Manual of Systematic Bacteriology [8].

\section{Histopathological evaluation}

A total of $20(4 \mathrm{~mm}) \mathrm{V}$ shaped gingival biopsies of the peri-implant tissue that was connected to the implant were randomly obtained from both patient groups using a sterile size eleven scalpel. All biopsies were taken from the buccal periodontal tissue at the area 33 (16 biopsies), area 34 (3 biopsies) and area 35 (1 biopsy) so as to minimise differences in tissue structure. The biopsies were obtained under local anaesthesia. The local anaesthetic agent (Xylocain ${ }^{\circledR} 2 \%$ with 1:100.000 adrenaline, Astra Chemicals, Sweden) was injected into the vestibular mandibulary sulcus at least $1 \mathrm{~cm}$ from the proposed biopsy site in order to minimize local anaesthetic infiltration into the biopsy. The tissue was orientated in exactly the same way for all patients and immediately immersed into a $10 \%$ formalin solution. One or two sutures were used to achieve primary closure and all biopsy sites healed without complications.

The biopsies were cut into 5 micrometre thick sections and stained with Hematoxylin-Eosin. The sections were examined under a Leitz Laborlux 12 microscope (Ernst Leitz GmbH, Wetzlar, Germany). The presence of inflammatory cell infiltrates was then scored by using a modified scoring system, originally described by Tagge et al. [9] and later modified by Adell et al. [1] and Lekholm et al. [11].

To score the material microscopically, criteria for no, normal, low, mild, moderate, and severe degrees of gingival inflammation were established according to the density of the inflammatory cells. The following modified system of scoring was used:

- $0 \rightarrow$ No inflammation.

- $1 \rightarrow$ Normal gingiva: scattered areas of chronic inflammatory cells were accepted as normal, if the cells occurred singly or in small bands.

- $2 \rightarrow$ Low inflamed gingiva: an accumulation of
- chronic inflammatory cells of small bands that were not continuous.

- $3 \rightarrow$ Mildly inflamed gingiva: an accumulation of chronic inflammatory cells that formed a thin, continuous band.

- $\quad 4 \rightarrow$ Moderately inflamed gingiva: a dense infiltrate of chronic inflammatory cells that replaced the gingival fibres.

- $5 \rightarrow \quad$ Severely inflamed gingiva: a generalized, dense accumulation of chronic inflammatory cells that replaced most of the gingival fibres.

\section{Biochemical and mechanical evaluation}

The volume of crevicular fluid in the implant sulcus was measured using a Periotron ${ }^{\circledR}$ (Harco Electronics, Dental Products Division, Winnipeg, Canada). Periopaper ${ }^{\mathrm{B}}$ (Harco Electronics) was inserted into the implant sulcus for 10 seconds, and was then placed between the upper and lower counterparts of the Periotron ${ }^{\circledR}$. The volume of crevicular fluid was measured as Periotron ${ }^{\circledR}$ units. The principle of the Periotron ${ }^{\circledR}$ is to measure the frequency circuit containing the condensor made from the two Periotron ${ }^{\circledR}$ counterparts and the Periopaper ${ }^{\circledR}$.

The hygiene-index (HI) was determined by staining the bacterial deposits on the implant with a colouring solution (MIRA 2-Tone ${ }^{\circledR}$, Disclosing Solution, Lorvic Corporation, St. Louis, MO, U.S.A.). The blue stain aided the detection of plaque. The presence of plaque was divided into four implant surfaces. The presence or absence (yes/no-decision) on all four implant surfaces divided by the total number of surfaces determined the index [15]. A HI-value of 100 indicated an implant free of plaque; a HI-value of 0 indicated plaque accumulation on all four surfaces of an implant.

Implant mobility was determined by using the Periotest ${ }^{\mathbb{B}}$ M (Medizintechnik Gulden, Germany) that detects the damping characteristics of the implant and the periimplant tissues as a whole. The range in Periotes ${ }^{\mathbb{B}} \mathrm{M}$ values shown by clinically immobile oral implants depends on the damping characteristics of their surrounding tissues with bone in successful implants and fibrous tissue marsupialization in failed implants.

\section{Masticatory function}

Masticatory function was evaluated using a chewing gum test. This method is used as an indicator of implant masticatory function [12]. The chewing gum (Meiji Chewing-Gum Co., Aichi, Japan) contains two bases (base A and B). Base A includes a lactone form (Phloxine), a food additive, and Base B includes sodium bicarbonate. The phloxine additive develops a red colour in alkaline conditions. To evaluate 
the masticatory function, both chewing gum components were given to the patient. Patients were instructed to make fifty chewing strokes at random (both the left and right sides of their oral cavity). Both chewing gum bases were mixed together by the process of mastication and a change in the colour of the chewing gum occurred.

The evaluation of the colour of the chewing gum was carried out immediately using the Chroma-Meter ${ }^{\circledR} \mathrm{CR}$ 200 (Minolta Camera Co., Ltd., Osaka, Japan) that uses a xenon lamp for colour analysis. This system evaluates the degree of colour of the chewing gum. The chewing gum developed a different colour as a result of mixing during mastication and, therefore, its light reflection value changed. The new colours were evaluated by using the $L^{*}, a^{*}, b^{*}$ colour system. The $\mathrm{L}^{*}, \mathrm{a}^{*}, \mathrm{~b}^{*}$ system is based on the recommendations of the Commission International de L' Eclairage (C.I.E., 1976). The degree of colour change from grey $\left(4.33 \mathrm{a}^{*}\right)$ to red (> $\left.4.33 \mathrm{a}^{*}\right)$ gave an approximate analysis of the masticatory function. Grey indicated a low and red a high masticatory function.

\section{Statistical analysis}

Statistical analysis was performed by using SPSS (SPSS Software, Chicago, Illinois, USA). Nonparametric methods were used to evaluate statistical significances. The groups were compared statistically using the Mann-Whitney U - Wilcoxon Rank Sum WTest for the evaluation of significances and the T-Test for equality of means. Spearman correlation coefficient was used for correlation analyses.

\section{RESULTS}

\section{Microbiological evaluation}

Microbiological examination of the crevicular fluid in both patient groups showed no evidence of Porphyromonas gingivalis, Prevotella intermedius, Actinobacillus actinomycetencomitans that are all known to be associated with peri-implant disease (Figure 3). The assessment of the oral mucosa flora proved to be normal, as only aerobic, microaerophillic, and anaerobic species of the normal mouth flora could be isolated (Figure 1). Staphylococcos aureus, which is considered a normal resident of the oral cavity, was present in the mouth flora of two patients.

The following two micro-organisms were isolated from both patient groups: Candida albicans and Enterococcus. Neither of these are usually associated with the subgingival micro flora in healthy adults with periodontitis [13]

\section{Histopathological evaluation}

Histopathological findings showed that all patients had histologically evident inflammation in the gingival area adjacent to the implant (Figures 2A and 2B).

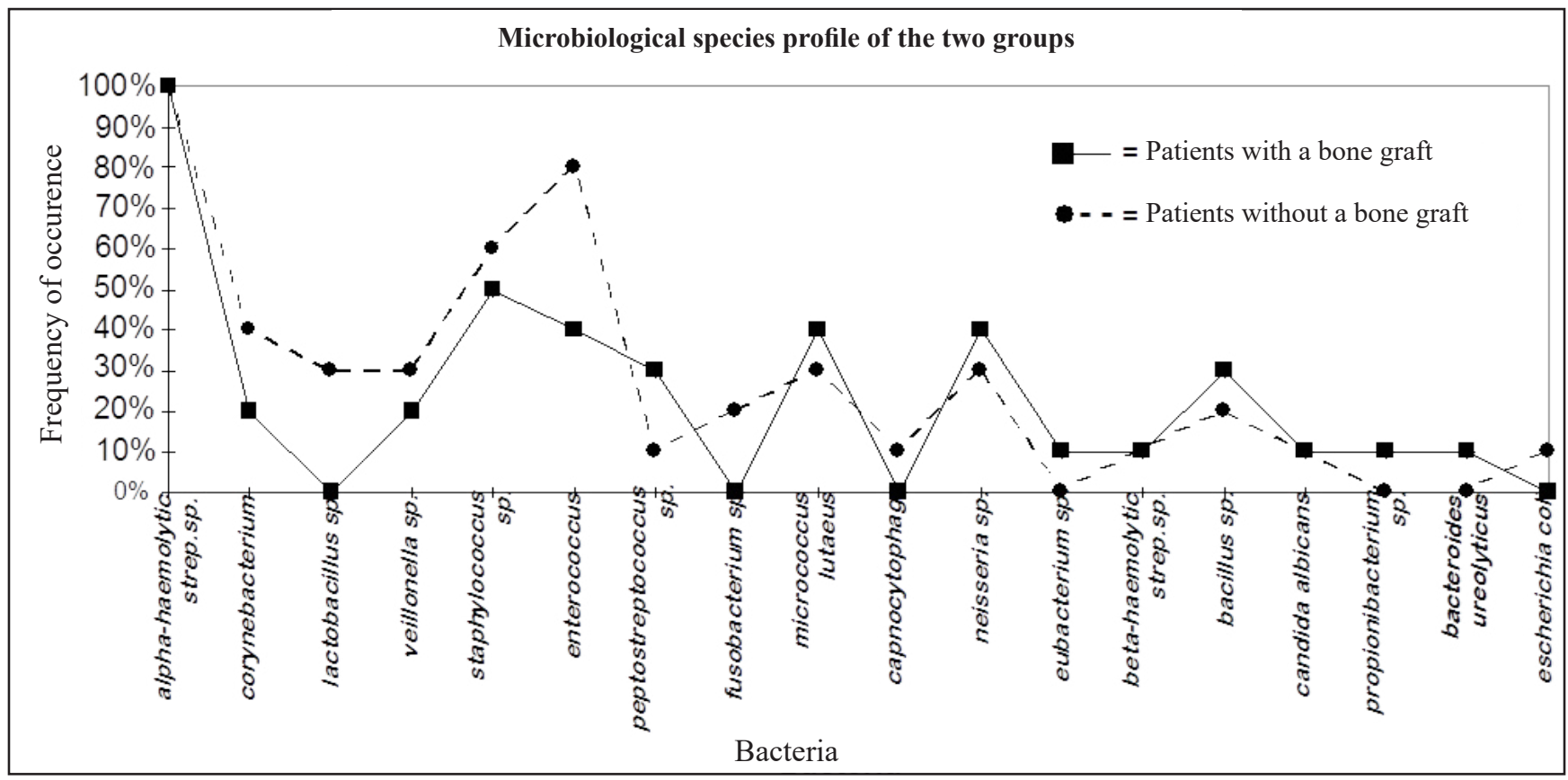

Figure 1. Microbiological examination of the crevicular fluid showed no evidence of the three most important pathogenic bacteria: Porphyromonas gingivalis, Prevotella intermedius, Actinobacillus actinomycetencomitans. 


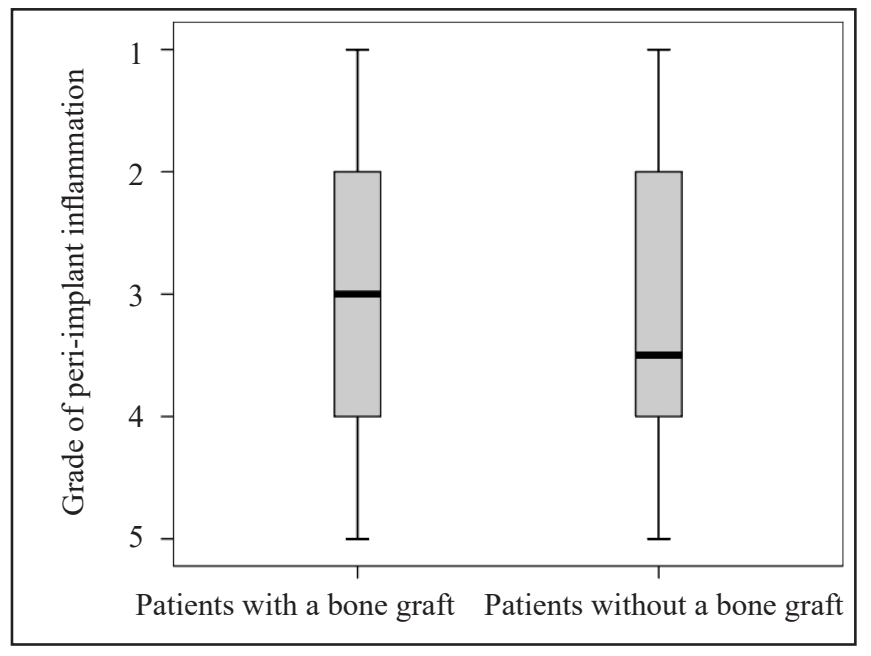

Figure 2A. Box-plot representing peri-implant inflammation: no significant difference was found between the two patient groups $(\mathrm{P}>0.05)$.

There was a clear pattern of proliferation and increased density of mononuclear and polymorphonuclear cells in the sulcular epithelium around the implants. Based on microscopic findings, six non-specific categories of inflammation were identified using a modified inflammation score originally described by Tagge et al. [9]. The mean degree of the peri-implant inflammation was 2.9 ranging from 1 to 5 with a standard deviation of 1.37 .

\section{Biochemical and mechanical evaluation}

The mean crevicular fluid flow rate (CFFR) for all patients was 26.0 (SD 12.26) ranging from 4 to 45

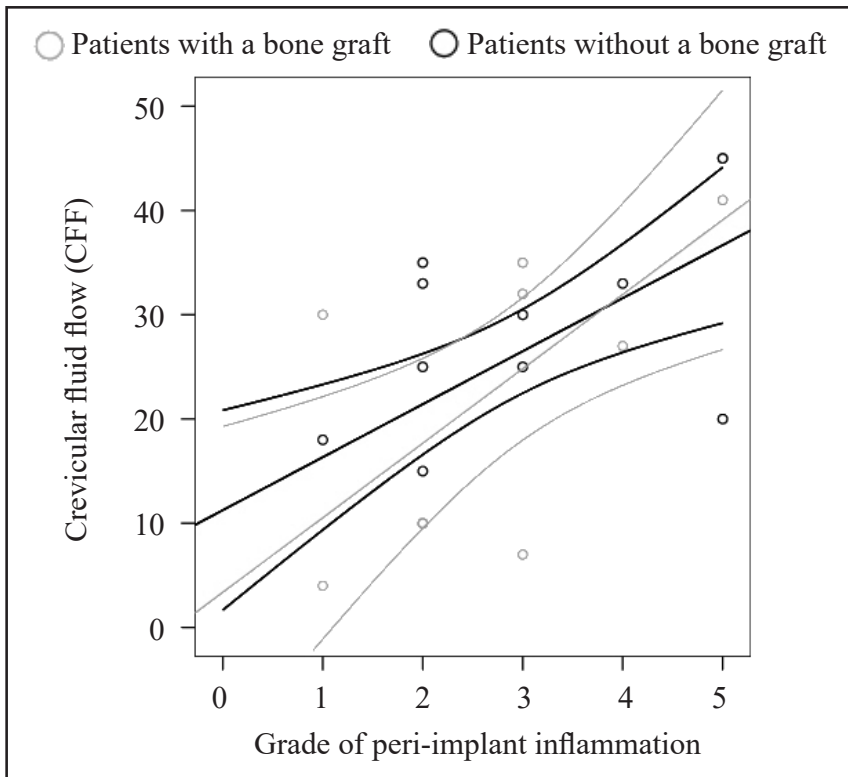

Figure 2B. The relationship between CFFR and inflammation score with $95 \%$ confidence intervals. The amount of crevicular fluid flow is compared to the grade of peri-implant inflammation.

(patients with a bone graft 24.1 [SD 15.06] and without a bone graft 27.9 [SD 9.09]) (Table 1). According to Dietrich et al. [14], CFFR mean values of 10 to 40 is a sign of slight gingival inflammation and values less than 10 show no signs of gingival inflammation. Values over 40 are considered as a sign of peri-implant tissue inflammation. In Figure 2B, the amount of crevicular fluid flow is compared to the grade of peri-implant inflammation. Figure 2B demonstrates that a high peri-implant inflammation is followed by an increase in the amount of crevicular fluid produced around

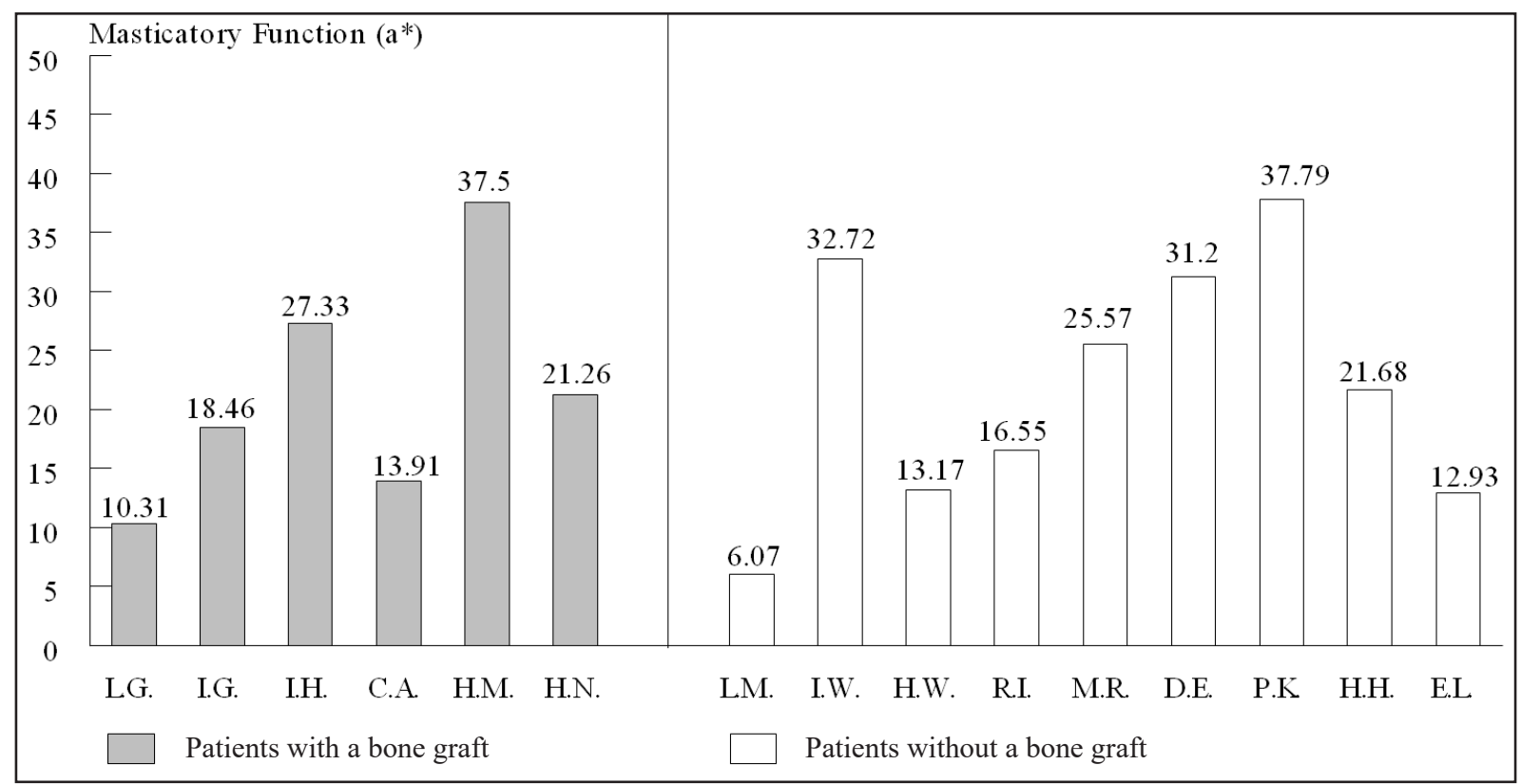

Figure 3. Graph showing masticatory function evaluation. The chewing-gum developed a different colour during mastication and, therefore, a different light reflection value. The degree of colour change from grey $\left(4.33 \mathrm{a}^{*}\right)$ to red $\left(>4.33 \mathrm{a}^{*}\right)$ gave an approximate analysis of the masticatory function. Grey is indicating a low and red a high masticatory function. 
Table 1. Recall-values of the patients without and with a bone graft

\begin{tabular}{|c|c|c|c|c|c|c|c|c|c|c|c|c|c|c|c|c|c|c|c|c|}
\hline \multirow[b]{2}{*}{ Recall-values } & \multicolumn{10}{|c|}{ Patients with a bone graft } & \multicolumn{10}{|c|}{ Patients without a bone graft } \\
\hline & L.G. & D.H. & K.K. & I.G. & I.F. & I.H. & G.H. & C.A & H.M. & H.N. & L.M. & I.W. & H.W. & R.I. & M.R. & I.H. & D.E. & P.K. & H.H. & E.L. \\
\hline Hygiene-Index & 100 & 100 & 50 & 100 & 100 & 75 & 0 & 0 & 100 & 75 & 50 & 100 & 100 & 100 & 100 & 100 & 100 & 75 & 75 & 0 \\
\hline Periotest $^{\circledR}$ & -1 & -5 & +3 & -4 & -3 & -3 & -4 & -3 & -3 & -5 & -1 & -3 & -4 & -3 & -4 & -4 & -3 & -4 & -4 & -3 \\
\hline Crevicular-Fluid-Flow & 4 & 27 & 35 & 7 & 10 & 10 & 32 & 41 & 30 & 45 & 20 & 15 & 35 & 25 & 45 & 30 & 33 & 25 & 18 & 33 \\
\hline
\end{tabular}

the peri-implant tissue. The correlation between crevicular fluid flow and peri-implant inflammation was $0.68(\mathrm{P}=0.029)$ in patients with a bone graft and 0.36 $(\mathrm{P}=0.31)$ in patients without a bone graft.

The mean HI was similar in both groups 80 (SD 32.91) ranging from 0 to 100 (Table 1 ). The mean Periotest ${ }^{\circledR}$ was -3.05 (SD 1.76) with a range from -5 to 3 and separately for patients with a bone graft -2.80 (SD 2.35) and for patients without a bone graft -3.30 (SD 0.30) (Table 1). According to Teerlink et al. [14] and Chavez et al. [15], these values suggest that all implants were clinically firm.

\section{Masticatory function}

The masticatory function test provided a functional analysis of the implants and their superstructures (Figure 2). The mean chewing-gum value for all patients was 21.76 (SD 10.64) a* ranging from 6.07 a* to 37.79 (patients with a bone graft 21.47 [SD 9.82] and for patients without a bone graft 21.96 [SD 10.64]) (Figure 2).

In a pilot study performed by Matsui et al. [12] on German patients, the following mean-values were described: 28.76 a* (SD 1.76) for fully dentate patients and $10.05 \mathrm{a}^{*}$ (SD 2.58) for patients with a full denture. The masticatory function was compared to the grade of peri-implant inflammation, and no significant correlation was observed. For patients with or without a bone graft the correlation values (rs) were respectively $-0.53(\mathrm{P}=0.28)$ and $0.11(\mathrm{P}=0.78)$. One patient had a lower chewing-function value than the mean value for patients with full dentures. In contrast, three patients achieved chewing-values of fully dentate patients. All other patients in the study had a satisfactory chewing function.

Similarly the masticatory function was compared to the Periotest values and no significant correlation was observed. For patients with or without a bone graft the correlation values (rs) were respectively 0.70 $(\mathrm{P}=0.13)$ and $0.11(\mathrm{P}=0.78)$.

\section{DISCUSSION}

Both patient groups showed similar microbiological and histological findings that indicated an early form of peri-implantitis. Microbiota associated with periimplant disease have often been reported to be similar to the microbiota associated with periodontitis such as P.gingivalis, P. intermedia and A. actinomycetencomitans $[\underline{17}, \underline{18}, \underline{19}]$.

Surprisingly, none of the above-mentioned bacteria could be isolated. One explanation why the microflora around the implants of our patients could be different is due to the fact that they were all edentulous. The bacteria colonizing our patients originated primarily from the surfaces of adjacent soft tissues in comparison to partially edentulous patients, whose dental microflora could have originated from the adjacent dentition. This consequently leads to new questions regarding possible differences in the microbial environment of edentulous and non edentulous patients. One interesting finding was the high presence of Staphylocaccus aureus in $60 \%$ of the non-grafted and $50 \%$ of the grafted patients this has also been reported by Renvert et al. [17]. The cause affect relationship in our patients with higher peri-implant inflammation could be due to hygienic neglect. However, a causal relationship between specific microbes and peri-implant inflammation could not be found. All biopsies displayed different amounts of lymphocytes, plasma cells, and granulocytes subjacent to the peri-implant epithelium. The periimplant inflammation could be due to plaque-associated micro-organisms that had accumulated around the periimplant sulcus. When the peri-implant inflammatory exudates were collected by using Periopaper $^{\circledR}$, it was not surprising to detect different levels of CFFR values. This could be due to the different number of protein fragments in the inflammatory exudates, depending on the degree of peri-implant inflammation. This corresponds to the results in the literature that show a direct relationship between CFFR values and the degree of peri-implant inflammation. 
The comparison between the inflammation score and the masticatory function (see results) show, that there is a slight tendency in patients with a bone graft to develop lower masticatory functions when the periimplant inflammation score is high. This result cannot be seen in patients without a bone graft. Furthermore a comparison between the masticatory function and the Periotest ${ }^{\circledR}$ values in both patient groups demonstrate that low Periotest ${ }^{\circledR}$ values $(-5 \rightarrow$ high; $0 \rightarrow$ low $)$ affect the masticatory function negatively.

The differences in the masticatory functions of the cancer patient group could be the result of change in the bone configuration hence bony structure after tumour surgery. Differences in the cancellous bone structure muscle strength and the elasticity of the jaw subsequently cause a different mechanical environment. Other factors, e.g., mechanical trauma from sharp exposed marginal fixtures threads against the mucosa may have also contributed to the development of lower masticatory values.

\section{CONCLUSIONS}

The microbiological species profile was almost identical in both patient groups. The microbiological examinations showed no evidence of the three most common pathogenic bacteria: Porphyromonas gingivalis, Prevotella intermedius, Actinobacillus actinomycetencomitans. It was not possible from the results of this study to claim proof for a direct cause and effect relationship between specific microorganisms and the tissue inflammation around the implants.

All biopsies in both patient groups revealed early signs of soft tissue peri-implant inflammation. The crevicular fluid volume and grade of gingival inflammation around the dental implants were related.

The only difference between the two patient groups was the slightly worse masticatory function in the oral cancer patients that had undergone reconstructive surgery, however this study shows that patients that have undergone reconstructive surgery can be successfully rehabilitated by means of bone grafts and dental implants resulting in improvements in eating ability and quality of life. Implant monitoring and oral care is of the utmost importance for patients who have undergone reconstructive surgery.

\section{ACKNOWLEDGMENTS AND DISCLOSURE STATEMENTS}

This work was carried out in the Department of Oral and Maxillofacial Surgery, Hanover University (M.H.H.), Germany. During these studies, many colleagues collaborated and we hold them in high regard. We wish to extend our warmest thanks to all those in the Department of Oral and Maxillofacial Surgery and the other Departments with whom we worked closely.

Special thanks to Mika Helminen for his statistical advice.

The authors declare that they have no conflict of interest.

\section{REFERENCES}

1. Kolokythas A. Long-Term Surgical Complications in the Oral Cancer Patient: a Comprehensive Review. Part II, J Oral Maxillofac Res 2010 (Jul-Sep);1(3):e2. [URL: http://www.ejomr.org/JOMR/archives/2010/3/e2/e2ab.htm] [doi: $10.5037 /$ jomr.2010.1302]

2. Chung WE, Rubenstein JE, Phillips KM, Raigrodski AJ. Outcomes assessment of patients treated with osseointegrated dental implants at the University of Washington Graduate Prosthodontic Program, 1988 to 2000. Int J Oral Maxillofac Implants. 2009 Sep-Oct;24(5):927-35. [Medline: 19865634]

3. Sàndor GK, Carmichael RP, Binahmed A. Reconstruction of Ablative Defects Using Dental Implants. Atlas of the Oral and Maxillofacial Clinics of North America. 2008; 16: 107-23.

4. Lachmann S, Kimmerle-Müller E, Axmann D, Gomez-Roman G, Weber H, Haas R. Reliability of findings around healthy implants in association with oral hygiene measures: a clinical, microbiological, and immunological follow-up in edentulous patients. Clin Oral Implants Res. 2007 Dec;18(6):686-98. [Medline: 17991251] [doi: 10.1111/j.1600-0501.2007.01399.x]

5. Graves CE, DeBiase CB. Survey of recall systems in dental hygiene programs. J Dent Hyg. 1989 Feb;63(2):79-81. [Medline: 2600641]

6. van Winkelhoff AJ, van der Avoort PG, Wismeijer D. [Infectious complications with dental implants]. Ned Tijdschr Tandheelkd. 2009 Apr;116(4):193-7. Review. Dutch. [Medline: 19438075]

7. Isenberg HD. Interpretation of aerobic bacterial growth on primary culture media. In: Clinical microbiology procedures handbook. Washington: American Society for Microbiology; 1992. p.161-7.

8. Balows A, Hausler WJ, Herrmann KL, Isenberg HD, Shadomy HJ. Streptococcus and related catalase-negative grampositive cocci. In: Facklam RR, Washington JA, editors. Manual of clinical microbiology. Washington: American Society for Microbiology, 1991. P. 238-57. 
9. Tagge DL, O'Leary TJ, El-Kafrawy AH. The clinical and histological response of periodontal pockets to root planing and oral hygiene. J Periodontol. 1975 Sep;46(9):527-33. [Medline: 1099189]

10. Adell R, Lekholm U, Rockler B, Brånemark PI, Lindhe J, Eriksson B, Sbordone L. Marginal tissue reactions at osseointegrated titanium fixtures (I). A 3-year longitudinal prospective study. Int J Oral Maxillofac Surg. 1986 Feb;15(1):39-52. [Medline: 3083005] [doi: 10.1016/S0300-9785(86)80010-2]

11. Lekholm U, Adell R, Lindhe J, Brånemark PI, Eriksson B, Rockler B, Lindvall AM, Yoneyama T. Marginal tissue reactions at osseointegrated titanium fixtures. (II) A cross-sectional retrospective study. Int J Oral Maxillofac Surg. 1986 Feb;15(1):53-61. [Medline: 3083006] [doi: 10.1016/S0300-9785(86)80011-4]

12. Matsui Y, Neukam FW, Wichmann M, Ohno K. Application of a low-adhesive color-developing chewing gum system to patients with osseointegrated implant-supported prostheses. Int J Oral Maxillofac Implants. 1995 Sep-Oct;10(5):583-8. [Medline: 7591003]

13. Brooks GF, Butel JS, Morse SA. The Streptococci. In: Jawetz, Melnick, Adelberg Medical Microbiology. California: Lange Medical Books, 1998. p. 197-202.

14. Dietrich U, Skop P. Recall. In: Tetsch P, editor. Enossale Implantationen in der Zahnheilkunde: Ein Atlas und Lehrbuch. Wien: Carl Hanser Verlag, 1991. p. 232-44.

15. Teerlinck J, Quirynen M, Darius P, van Steenberghe D. Periotest: an objective clinical diagnosis of bone apposition toward implants. Int J Oral Maxillofac Implants. 1991 Spring;6(1):55-61. [Medline: 1843494]

16. ChavezH, Ortman LF, DeFranco RL, Medige J.Assessment of oral implant mobility. J Prosthet Dent. 1993 Nov;70(5):421-6. [Medline: 8254544] [doi: 10.1016/0022-3913(93)90078-3]

17. Renvert S, Persson GR. Periodontitis as a potential risk factor for peri-implantitis. J Clin Periodontol. 2009 Jul;36 Suppl 10:9-14. Review. [Medline: 19432626] [doi: 10.1111/j.1600-051X.2009.01416.x]

18. Mombelli A. Microbiology and antimicrobial therapy of peri-implantitis. Periodontol 2000. 2002;28:177-89. Review. [Medline: 12013341] [doi: 10.1034/j.1600-0757.2002.280107.x]

19. Quirynen M, De Soete M, van Steenberghe D. Infectious risks for oral implants: a review of the literature. Clin Oral Implants Res. 2002 Feb;13(1):1-19. Review. [Medline: 12005139] [doi: 10.1034/j.1600-0501.2002.130101.x]

20. Renvert S, Roos-Jansåker AM, Lindahl C, Renvert H, Rutger Persson G. Infection at titanium implants with or without a clinical diagnosis of inflammation. Clin Oral Implants Res. 2007 Aug;18(4):509-16. Epub 2007 May 21. [Medline: 17517058] [doi: 10.1111/j.1600-0501.2007.01378.x]

\section{To cite this article:}

Wolff J, Agata H, Sándor GK, Haimi S. Peri-Implant Tissue Findings in Bone Grafted Oral Cancer Patients Compared to non Bone Grafted Patients without Oral Cancer.

J Oral Maxillofac Res 2011;2(4):e2

URL: http://www.ejomr.org/JOMR/archives/2011/4/e2/v2n4e2ht.pdf

doi: $10.5037 /$ jomr.2011.2402

Copyright (C) Wolff J, Agata H, Sándor GK, Haimi S. Accepted for publication in the JOURNAL OF ORAL \& MAXILLOFACIAL RESEARCH (http://www.ejomr.org), 23 August 2011.

This is an open-access article, first published in the JOURNAL OF ORAL \& MAXILLOFACIAL RESEARCH, distributed under the terms of the Creative Commons Attribution-Noncommercial-No Derivative Works 3.0 Unported License, which permits unrestricted non-commercial use, distribution, and reproduction in any medium, provided the original work and is properly cited. The copyright, license information and link to the original publication on (http://www.ejomr.org) must be included. 